\title{
A Simulink / MATLAB Model of a Three-Phase Sinusoidal PWM Inverter Driven Induction Motor
}

\author{
Aleck W. Leedy, Tanner Grider, Rebekah Priddy
}

\begin{abstract}
A three-phase voltage source inverter driven induction motor dynamic model developed using Simulink / $M A T L A B$ is presented. The presented model is derived from the d-q motor model. A modular approach is used in the construction of the motor-drive system model. The model presented is useful for studying both the steady-state and transient behavior of the motor drive system. The developed model enables the user to access all parameters of interest. Modifications can be made to the system model in order for it to be used with other motor drive system topologies. The model has benefits for use by undergraduate student researchers, and professors when used as a teaching tool in undergraduate courses.
\end{abstract}

Index Terms- PWM, Induction Motor, Inverter, and Simulink .

\section{INTRODUCTION}

The use of software packages such as Simulink / MATLAB, PSPICE, etc. have become a vital tool for performance prediction and system behavior of motor-drives [1]. The transient behavior of a motor-drive system is of interest due to this type of system typically needing speed and torque control [3]. Simulation studies help to validate the design process and reduce design errors [1]. An understanding of electrical transients can be acquired from dynamic models of electric machines [4]. Dynamic models can aid in the selection of the appropriate machine for a specific operation [5]. Various Simulink models of induction motors can be found [6]. Many of the models do not allow access to all parameters.

A dynamic model of a three-phase induction motor drive system such as the one shown in Fig. 1 is presented in this paper. The figure shows a DC voltage source connected to a three-phase inverter driving a three-phase induction motor with a load attached. The model presented will be useful to

Revised Manuscript received on September 11, 2019.

* Correspondence Author

Dr. Aleck W. Leedy*, P.E., Institute of Engineering, Murray State University, Murray, KY, U.S.A., e-mail: aleedy@murraystate.edu.

Tanner Grider, Electrical \& Computer Engineering Dept., Auburn University, Auburn, AL, U.S.A.

Rebekah Priddy, Institute of Engineering, Murray State University, Murray, KY, U.S.A.

(C) The Authors. Published by Blue Eyes Intelligence Engineering and Sciences Publication (BEIESP). This is an open access article under the CC BY-NC-ND license (http://creativecommons.org/licenses/by-nc-nd/4.0/) people with elementary level knowledge of electric machines up to advanced / expert level knowledge. The developed model will allow access to all inverter and motor parameters.

The use of pulse width modulation is frequently utilized in variable-speed electric drive systems [3, 4]. Various pulse width modulation techniques and schemes have been the main topic of interest to researchers in the power electronics area for years. Bennett [7] was the first researcher to study modulated pulses in 1933. Since Bennett's studies, several schemes have been developed to shape the output waveform of an inverter.

The Simulink Power System Blockset includes models of various types of electric machines. However, all machine variables are not readily accessible. A researcher can build their own model of an induction motor that will provide access to all variables using basic building blocks from Simulink. This approach is advantageous to researchers with limited research funds. This is also a good opportunity to have undergraduate students get involved with electric machine research by having them work on the Simulink model.

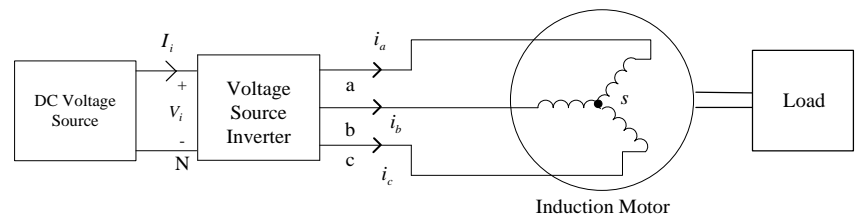

Fig. 1. Induction Motor-Drive Block Model.

\section{DYNAMIC MODEL OF THE MOTOR}

The d-q or dynamic equivalent circuit of the induction motor as represented in the rotating reference frame shown in Fig. 2 [8] is used for all analyses, with quantities referred to the stator. For reference, the steady-state model of the induction motor is examined in [9]. Analysis of the circuits shown in Fig. 2 produces the following differential equations [8]:

$v_{d s}=R_{s} i_{d s}+\frac{d \lambda_{d s}}{d t}-\omega_{e} \lambda_{q s}$,

$v_{q s}=R_{s} i_{q s}+\frac{d \lambda_{q s}}{d t}+\omega_{e} \lambda_{d s}$,

$v_{d r}=0=R_{r} i_{d r}+\frac{d \lambda_{d r}}{d t}-\left(\omega_{e}-\omega_{r}\right) \lambda_{q r}$,

and

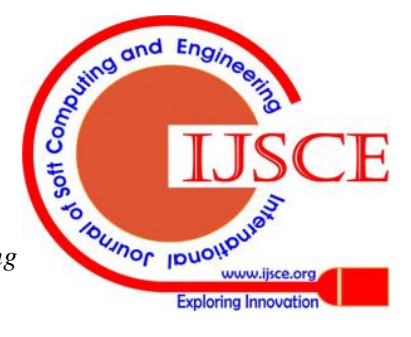


$v_{q r}=0=R_{r} i_{q r}+\frac{d \lambda_{q r}}{d t}+\left(\omega_{e}-\omega_{r}\right) \lambda_{d r}$

where subscript $d$ is the direct axis, $q$ is the quadrature axis, $r$ is the rotor, and $s$ is the stator in (1-4). The angular velocity of the reference frame is $\omega_{e}$, the angular velocity of the rotor is $\omega_{r}$, and $\lambda_{d s}, \lambda_{d s}, \lambda_{d s}$, and $\lambda_{d s}$ are flux linkages. The fact that the motor analyzed is a squirrel cage machine leads to the rotor voltage in (3) and (4) being zero.

The electromagnetic torque of the machine can be expressed as [8]:

$$
T_{e}=\frac{3}{2} \frac{P}{2} L_{m}\left[i_{q s} i_{d r}-i_{d s} i_{q r}\right]
$$

where $P$ is the number of poles. Neglecting the mechanical damping leads to a relationship between torque and rotor speed as:

$\frac{d \omega_{r}}{d t}=\frac{P}{2 J}\left(T_{e}-T_{L}\right)$

where $T_{L}$ is the load torque and $J$ is the inertia of the rotor and connected load. Integrating the frequency of the input voltages yields the angle, $\theta_{e}$, as follows:

$\theta_{e}=\int_{0}^{t} \omega_{e} d t+\theta_{e}(0)$

where $\theta_{e}(0)$ is the initial rotor position. [8]:

The following voltage transformation matrix can be used

$\left[\begin{array}{c}v_{q s}^{s} \\ v_{d s}^{s}\end{array}\right]=\left[\begin{array}{ccc}1 & 0 & 0 \\ 0 & \frac{-1}{\sqrt{3}} & \frac{1}{\sqrt{3}}\end{array}\right]\left[\begin{array}{l}v_{a n} \\ v_{b n} \\ v_{c n}\end{array}\right]$

where the superscript $s$ in (8) refers to the stationary frame. Conversion of the voltages in (8) to the synchronously rotating frame can be accomplished by using:

$v_{q s}=v_{q s}^{s} \cos \theta_{e}-v_{d s}^{s} \sin \theta_{e}$,

and

$v_{d s}=v_{q s}^{s} \sin \theta_{e}+v_{d s}^{s} \cos \theta_{e}$.

The currents can be written as:

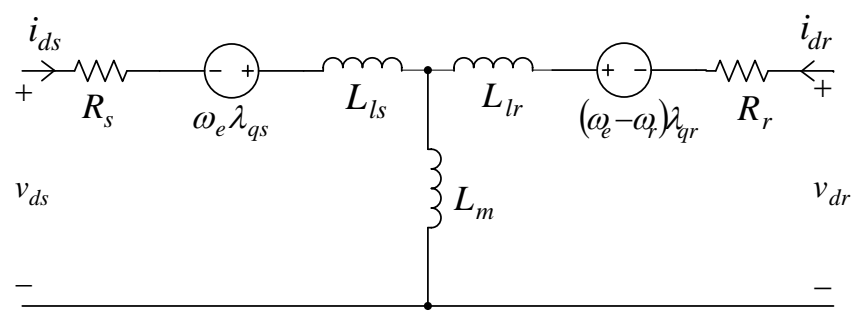

$d$-axis circuit
Published By:

Blue Eyes Intelligence Engineering

\& Sciences Publication

(C) Copyright: All rights reserved.

Fig. 2. d-q Motor Model [8].

$i_{q s}^{s}=i_{q s} \cos \theta_{e}+i_{d s} \sin \theta_{e}$

$i_{d s}^{s}=-i_{q s} \sin \theta_{e}+i_{d s} \cos \theta_{e}$,

and

$\left[\begin{array}{l}i_{a} \\ i_{b} \\ i_{c}\end{array}\right]=\left[\begin{array}{ll}1 & 0 \\ \frac{-1}{2} & \frac{-\sqrt{3}}{2} \\ \frac{-1}{2} & \frac{\sqrt{3}}{2}\end{array}\right]\left[\begin{array}{l}i_{q s}^{s} \\ i_{d s}^{s}\end{array}\right]$

A more detailed derivation of flux linkages, currents, etc. can be found in [10]. The focus of this paper is more on the voltage source inverter block of Fig. 1.

\section{THREE-PHASE VOLTAGE SOURCE INVERTER}

The control signals and the carrier waveform of a three-phase voltage source inverter operating as a two-level PWM inverter with sine-triangle modulation is shown in Fig. 3. The control signals shown in Fig. 3 can be expressed as:

$$
\begin{aligned}
& v_{\text {control }_{a}}(t)=V_{\text {con }} \sin \omega_{1} t, \\
& v_{\text {control }_{b}}(t)=V_{\text {con }} \sin \left(\omega_{1} t-120^{\circ}\right), \\
& v_{\text {control }_{c}}(t)=V_{\text {con }} \sin \left(\omega_{1} t+120^{\circ}\right),
\end{aligned}
$$

where, $V_{\text {con }}$ is the peak amplitude of the control signal, and $\omega_{1}$ is the angular frequency.

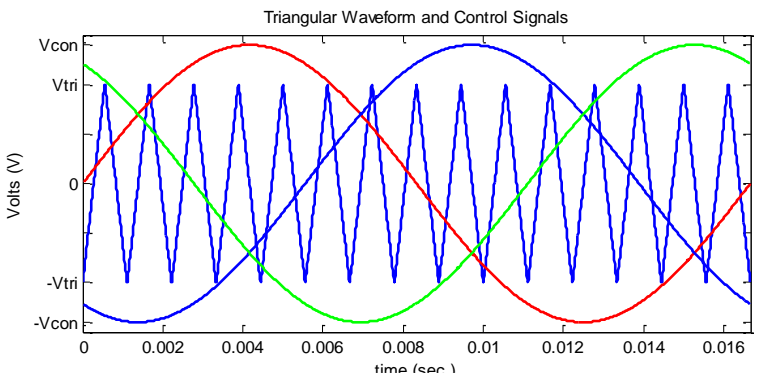

Fig. 3. Three-Phase Sinusoidal PWM Control Signals and Carrier Waveform.

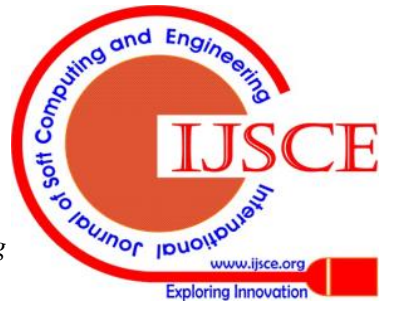


The crossing points of the control signals and the carrier waveform in Fig. 3 set the width of the pulses of the line-to-negative DC bus voltage waveforms (the negative DC bus is denoted with an $\mathrm{N}$ in Fig. 1) as shown in Fig. 4.

The inverter line-to-neutral voltages can be written as:

$v_{a s}(t)=v_{a N}(t)-v_{s N}(t)$,

$v_{b s}(t)=v_{b N}(t)-v_{s N}(t)$, and

$v_{c s}(t)=v_{c N}(t)-v_{s N}(t)$.

Assuming balanced operating conditions, the following condition for the inverter voltages must hold:

$v_{a s}(t)+v_{b s}(t)+v_{c s}(t)=0$.

The following relationship can be obtained by substituting (17-19) into (20):

$v_{s N}(t)=\frac{1}{3}\left[v_{a N}(t)+v_{b N}(t)+v_{c N}(t)\right]$.

Substitution of (21) into (17) produces the phase $a$ line-to-neutral voltage as:

$v_{a s}(t)=\frac{2}{3} v_{a N}(t)-\frac{1}{3} v_{b N}(t)-\frac{1}{3} v_{c N}(t)$.

The phase $b$ and phase $c$ line-to-neutral voltages can be found in a similar manner. The phase $a$ voltage waveform for the system in Fig. 1 is shown in Fig. 5.
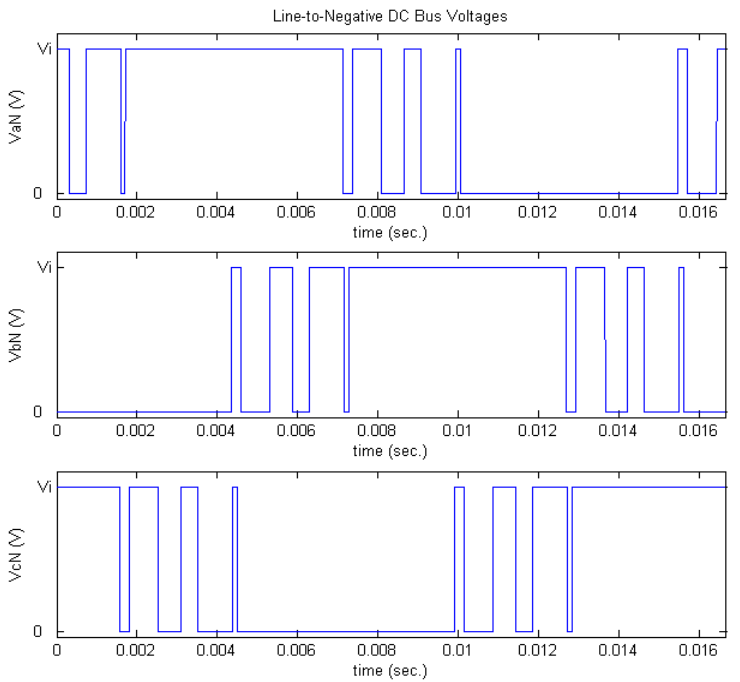

Fig. 4. Line-to-Negative DC Bus Voltage Waveforms.
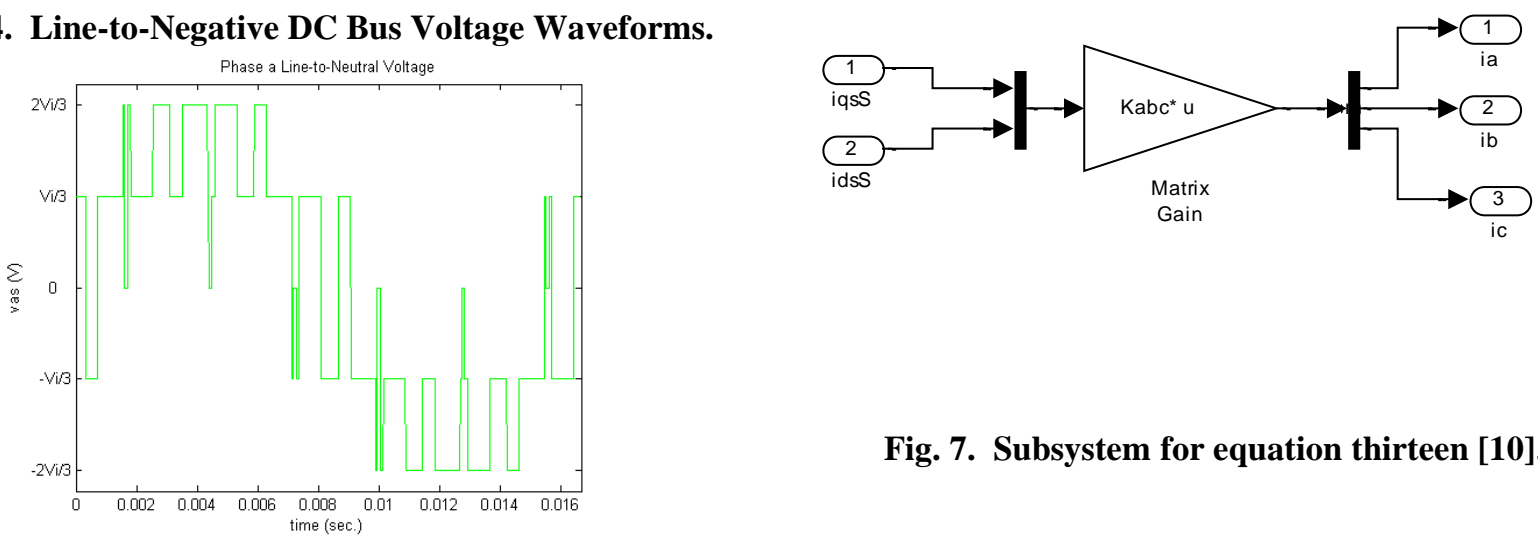

Fig. 7. Subsystem for equation thirteen [10].

A modular approach [11] will be utilized for constructing the Simulink model presented. This approach allows the model to be built in a "drag and drop" manner similar to PSPICE. This paper makes additions and modifications to the model presented in [10] to accommodate controlling the switches of the three-phase inverter in Fig. 1 to operate as a two-level sinusoidal PWM inverter.

The Simulink model can be developed by using (1-13). The motor equations can be used to divide the Simulink model into subsystems. The subsystems are each created using one of the model equations from (1-13). Fig. 6, 7, and 8 show some of the subsystems that are used to create the main top-level model. Fig. 6 implements (5), Fig. 7 implements (13), and Fig. 8 implements (6). Only basic Simulink blocks such as the integrator, gain, sum, etc. are needed to construct the proposed model. The use of basic blocks avoids having to purchase extra toolboxes that could add to the research expenses of professors at teaching focused schools.

The model in [10] was modified in this paper in order to control the switches of the three-phase inverter in Fig. 1 to operate as a two-level sinusoidal PWM inverter. In order to accomplish this, a new subsystem was developed. The subsystem that implements the two-level sinusoidal PWM portion of the model is shown in Fig. 9. This subsystem implements (14-16) using the sine wave generator block in Simulink. The triangle waveform in Fig. 3 is generated using the triangle generator block in Simulink. The relational operator block in Simulink is used for comparison of the control signals and the carrier waveform from Fig. 3. Gain and summing blocks are used to produce the phase $a$ line-to-neutral voltage as in (22). Phase b and phase $c$ line-to-neutral voltages are produced in a similar manner. The upper-level model with all of the subsystems connected together is shown in Fig. 10.

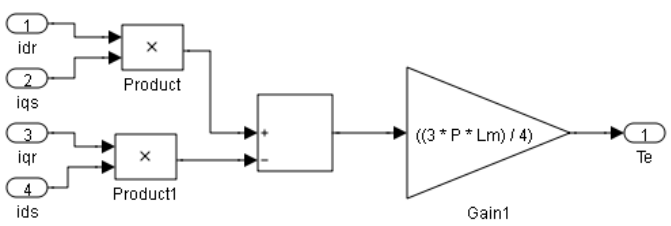

Fig. 6. Subsystem for equation five [10].

Fig. 5. The Phase a Voltage Produced using MATLAB.

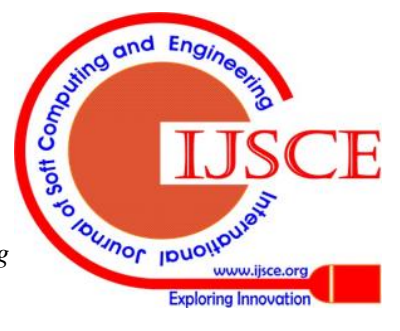




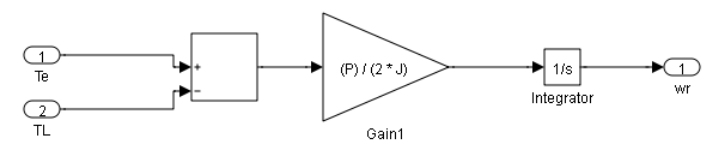

Fig. 8. Subsystem for equation six [10].

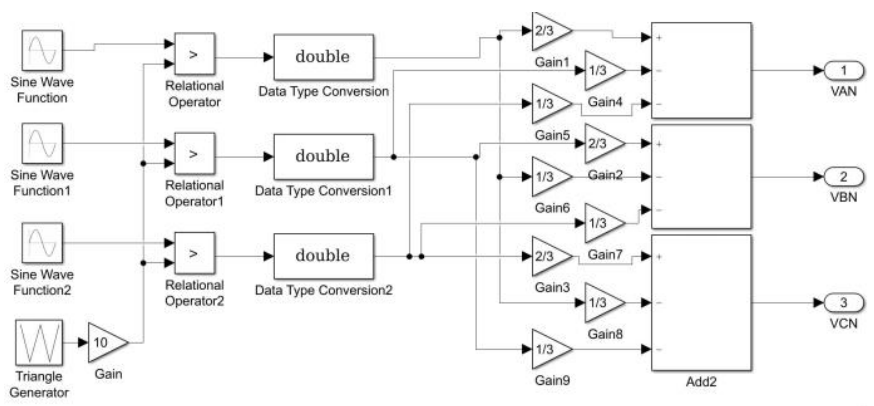

Fig. 9. Subsystem for the PWM block.

It is best when starting to build the system model shown in Fig. 10 to look at developing the individual subsystem for each system equation. After the individual subsystems have been developed, the subsystems can be tied together to produce the entire system model. The MATLAB editor can also be utilized when developing the system model of the induction motor drive. For example, an $m$ file can be written for the Kabc matrix shown in Fig. 7. The matrix can be defined in an $m$ file, and the Simulink model can be simulated by running the $m$ file. The various induction motor parameters can be declared in an $m$ file for use with the Simulink model. The inverter parameters can also be declared in an $m$ file. For the undergraduate student / researcher with elementary level knowledge of electric machines, it is best to start with a simple system to model in Simulink such as a single first order linear constant coefficient differential equation before attempting to build the entire motor drive model. This approach will allow time to see how block models are developed in Simulink using the basic blocks such as the integrator, gain, sum, etc.

\section{SIMULINK RESULTS}

Simulink was used to simulate the system shown in Fig. 1 using the developed model shown in Fig. 10. The voltage source inverter in Fig. 1 was operating as a two-level sinusoidal PWM inverter during the simulation. The DC input voltage to the inverter was $V_{i}=460 \mathrm{~V}$. The inverter parameters used in the Simulink model were as follows: $f_{1}=$ $60 \mathrm{~Hz}, m_{a}=1.4$, and $m_{f}=15$. A plot of the phase $a$ voltage at the input terminals of the induction motor during the simulation is shown in Fig. 11. The parameters used for the induction motor during the simulation were: $R_{1}=0.087 \Omega$, $R_{2}=0.228 \Omega, L_{m}=34.7 \mathrm{mH}, L_{l s}=0.8 \mathrm{mH}, L_{l r}=0.8 \mathrm{mH}, J=1.662 \mathrm{~kg}$ $\mathrm{m}^{2}, P=4$, and $H P=50$. A pulsed torque load was applied with the following characteristics: $T_{L}=150 \mathrm{~N}-\mathrm{m}, T=10 \mathrm{~s}$, and $D=4 / 5$.

A plot of the load torque and the rotor angular velocity is shown in Fig. 12. The electromagnetic torque and the stator current for phase $a$ is shown in Fig. 13. A second simulation was conducted at no-load. All motor and inverter parameters remained the same during the simulation. The torque and stator current plots are shown in Fig. 14.

\section{CONCLUSION}

A dynamic model of a voltage source inverter fed induction motor was developed in Simulink / MATLAB. The inverter operated as a two-level inverter with sine triangle modulation during the simulations presented. A modular approach was used in the construction of the Simulink model. The model presented enables the user to access all parameters of interest. The model is beneficial for undergraduate student research projects and for use in undergraduate courses.

\section{REFERENCES}

1. P. M. Menghal, A. J. Laxmi, and N. Mukhesh, "Dynamic Simulation of Induction Motor Drive Using Artificial Intelligent Controller," in Proceedings of The 2014 International Conference on Control, Instrumentation, Energy, and Communication (CIEC), 2014, pp. 301-305.

2. I.D. Smarandescu, R. Marinescu, M. Nicolae, and P. Nicolae, "Considerations on Designing and Simulation of an Induction Motor Drive System for an Electric Locomotive," in Proceedings of the 2017 International Conference on Modern Power Systems (MPS), June 69, 2017.

3. K.S. Gaeid, H.W. Ping, and H.A.F. Mohamed, "Indirect Vector Control of a Variable Frequency Induction Motor Drive," in Proceedings of the 2009 International Conference on Instrumentation, Communication, Information Technology, and Biomedical Engineering, pp. 36-40.

4. N. Kumar, T.R. Chelliah, and S.P. Srivastava, "Energy Conservation Study on Induction Motors using MATLAB/Simulink for Enhancing Electric Machinery Courses," in Proceedings of the 2012 IEEE International Conference on Teaching, Assessment, and Learning for Engineering, pp. H4B-10 - H4B-16.

5. P.S. Chaudhare, P.M. Patil, S.S. Patel, P.P. Kulkarni, and R.M Holmukhe, "Comparison of Performance Characteristic of Squirrel Cage Induction Motor by Three Phase Sinusoidal and PWM Inverter Supply using MATLAB Digital Simulation ," in Proceedings of the International Conference on Emerging Trends in Engineering and Technology (ICETET), Nov. 19-21, 2010.

6. A. Bentounsi, H.Djeghloud, H. Benalla, T. Birem, and H. Amiar, "Computer-Aided Teaching Using MATLAB / Simulink for Enhancing an IM Course With Laboratory Tests," IEEE Transactions on Education, vol. 54, no. 3, August 2011.

7. W.R. Bennett, "New Results in the Calculation of Modulation Products," The Bell System Technical Journal, vol. 12, Apr. 1933, pp. 228-243.

8. P.C. Krause, O. Wasynczuk, S.D. Sudhoff, and S. Pekarek, Analysis of Electric Machinery and Drive Systems, $3^{\text {rd }}$ Ed., Wiley - IEEE Press, NY: 2013.

9. A.W. Leedy and R.M. Nelms, "Simplified Model of an Inverter-Fed Induction Motor for the Analysis of a DC Power System", in Proceedings of the $36^{\text {th }}$ IEEE Southeastern Symposium on System Theory, 2004, pp. 275-279.

10. 10. A.W. Leedy, "Simulink / MATLAB Dynamic Induction Motor Model for use in Undergraduate Electric Machines and Power Electronics Courses", Proceedings of the IEEE SoutheastCon 2013, Hyatt Regency Jacksonville Riverfront, Jacksonville, FL, April 4-7, 2013, pp. 1-6.

11. B. Ozpineci and L.M. Tolbert " "Simulink Implementation of Induction Machine Model-A Modular Approach," in Proceedings of the IEEE International Electric Machines and Drives Conference (IEMDC), 2003, pp. 728-734.

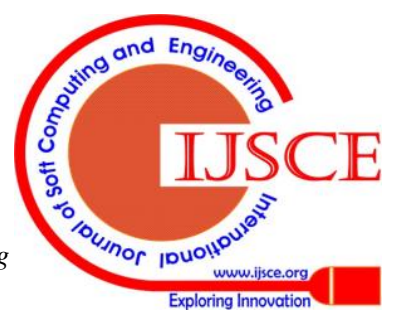




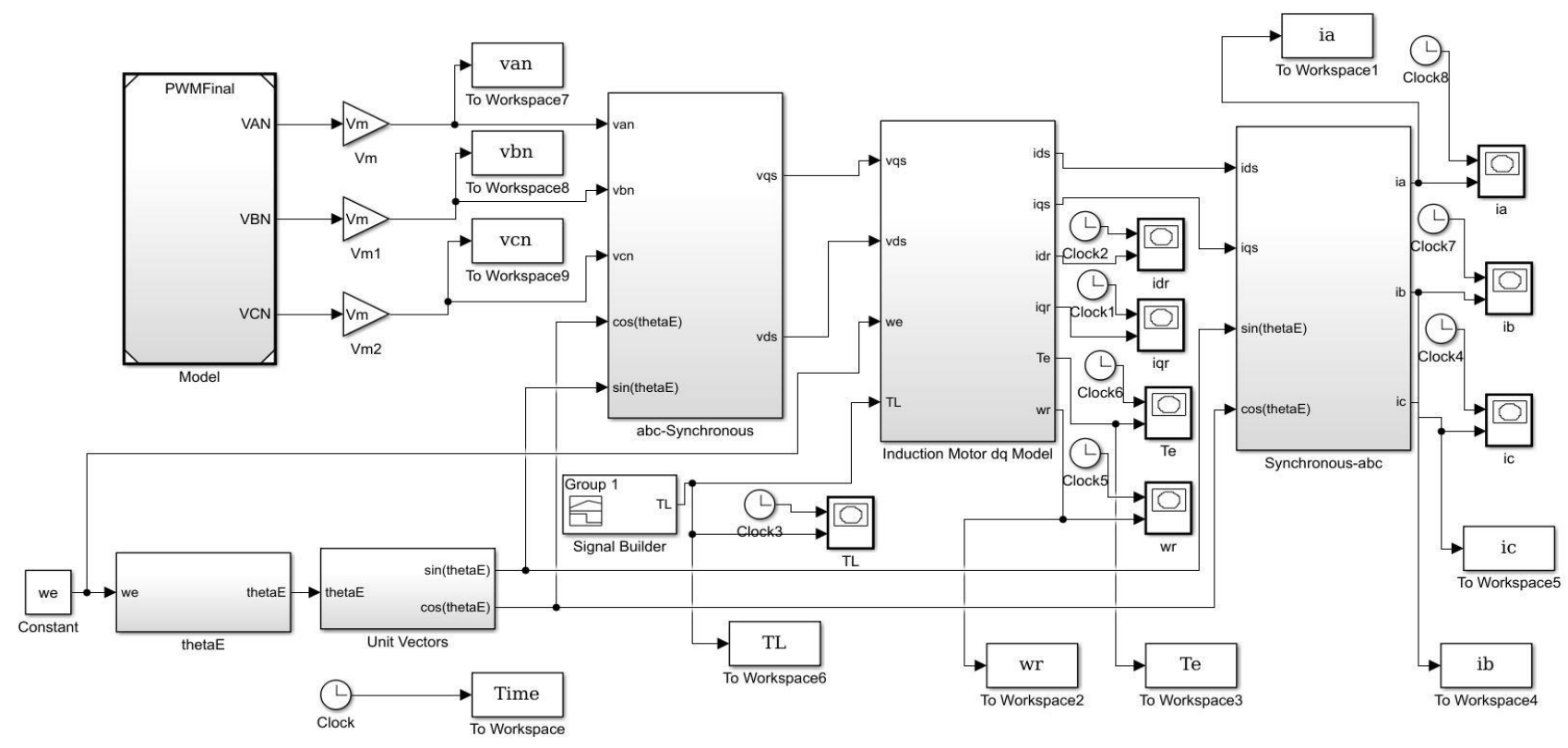

Fig. 10. Simulink Induction Motor-Drive Model.

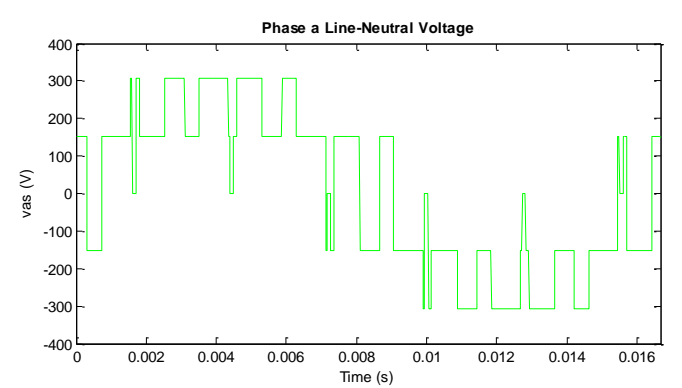

Fig. 11. Phase $a$ Voltage.
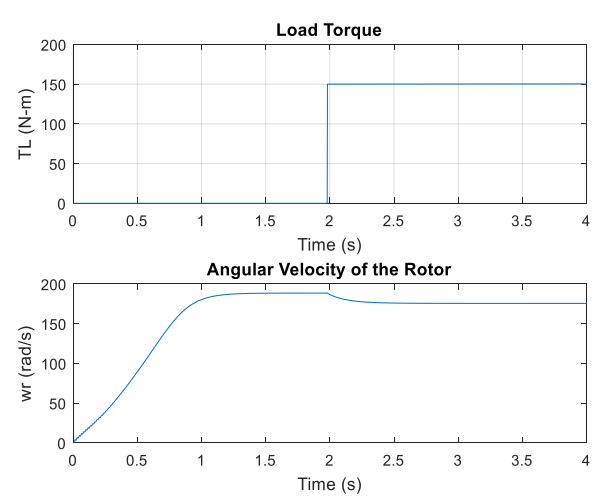

Fig. 12. Load Torque and Rotor Angular Velocity.
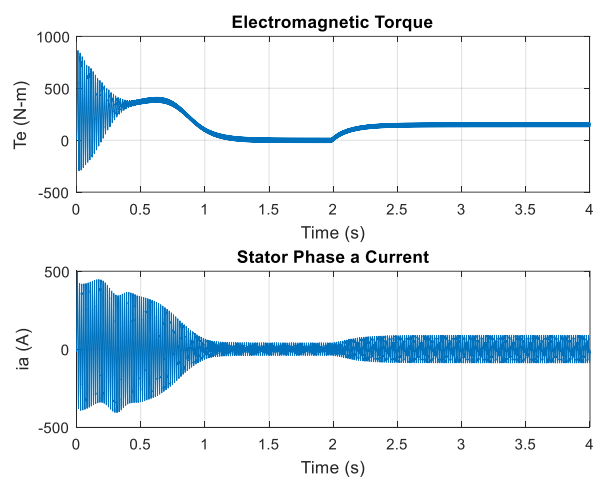

Fig. 13. Torque and Stator Current.
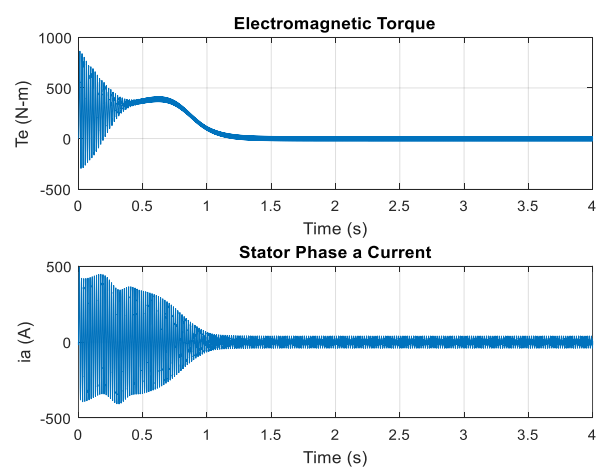

Fig. 14. Torque and Stator Current at No-Load.

Published By:

Blue Eyes Intelligence Engineering

\& Sciences Publication

(C) Copyright: All rights reserved.

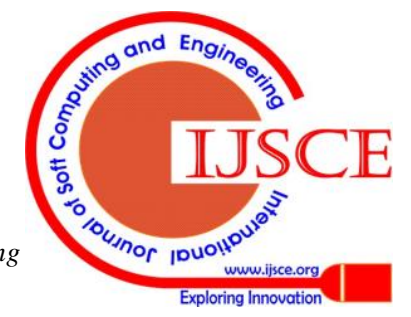




\section{A Simulink / MATLAB Model of a Three-Phase Sinusoidal PWM Inverter Driven Induction Motor}

\section{AUTHORS PROFILE}

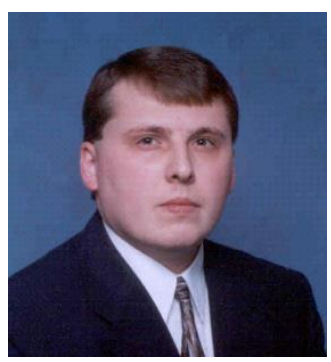

Aleck W. Leedy received the B.S. degree in electrical engineering and the M.S. degree in mining engineering from the University of Kentucky, Lexington, KY, and the Ph.D. degree in electrical engineering from Auburn University, Auburn, AL, in 1996, 2001, and 2006, respectively. He also received the Master of Applied Mathematics degree from Auburn University, Auburn, AL, in 2006.

He is currently an Associate Professor in the Institute of Engineering at Murray State University, Murray, KY. His teaching and research interests are in the areas of power systems, power electronics, and electric machines.

Dr. Leedy is a registered professional engineer in the Commonwealth of Kentucky. He is a Senior Member of IEEE, a member of the Order of the Engineer, and a member of the IEEE Industry Applications Society.

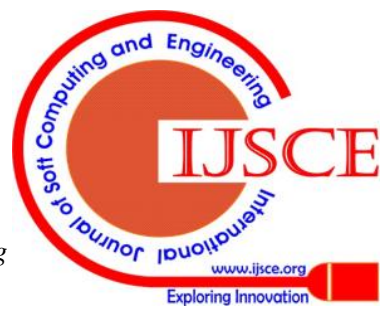

